\title{
Nutritional status and correlation with academic performance among primary school children, northwest Ethiopia
}

\author{
Biachew Asmare*, Mekuanint Taddele, Sileshi Berihun and Fasil Wagnew*
}

\begin{abstract}
Objective: This study aimed to determine the association between nutritional status and academic performance among primary school children in Debre Markos Town, northwest Ethiopia, 2017.

Results: The prevalence of stunting, underweight and wasting were $27.5 \%(95 \% \mathrm{Cl} 23.2-31.9 \%), 20.4 \%(95 \% \mathrm{Cl}$ $16.5-24.3 \%)$ and $8.7 \%$ (95\% Cl 6.2-11.5\%), correspondingly. The low level of educational performance was significantly higher $(p<0.05)$ among the stunted, underweight and wasted children than that of the normal children. In multivariable logistic regression, age of the child (Adjusted Odds Ratio $(A O R)=0.177,95 \% \mathrm{Cl} 0.07,0.4)$, monthly income less $<1000.00$ birr $(A O R=0.05,95 \% \mathrm{Cl} 0.02,0.15)$, stunted children $(A O R=0.21,95 \% \mathrm{Cl} 0.10,0.43)$ and under-weight $(A O R=0.63,95 \% \mathrm{Cl} 0.26,0.84)$ were associated with academic performance. This study revealed that indicators of undernutrition were prevalent among school-age children. Thus, collaboration between the health and education sectors is required to alleviate the problem.
\end{abstract}

Keywords: Academic performance, Nutritional status, School age children

\section{Introduction}

Quality education plays a pivotal role in the economic, social and political development. Currently, getting children into schools is not enough; government ensure that children attain the basic knowledge and skills needed for personal well-being [1]. Primary school is an important stage in the development of consciousness and personality of the child $[1,2]$.

Nutrition is also a vital component of human health, life, and brain development through the entire lifespan [3]. Balanced nutritious is crucial for endurance, physical growth, cognitive development and productivity [4]. As well, malnutrition is considered a pressing problem that affects the ability of children to learn and causes them to perform at a lower level in school [5-7]. Undernutrition is a major public health challenging affecting academic school achievement [8]. Ethiopia is one of the sub-Saharan African countries basically affected by

*Correspondence: asbia12@gmail.com; fasilw.n@gmail.com College of Health Sciences, Debre Markos University, PO. Box: +251-269, Debre Markos, Ethiopia child malnutrition. Previous studies conducted in different areas have shown that under nutrition is common among school-age children; it was reported in the form of stunting range from 11 to $48.7 \%$ and underweight from 7.2 to $59.7 \%$ [9]. A study conducted in eastern Ethiopia reported that the prevalence of stunting was $8.9 \%$, of which, $2 \%$ had severe stunted among school-aged children [10]. Though evidence about the prevalence of malnutrition is well studied in Ethiopia, there is insufficient evidence regarding nutritional status allied with academic performance among school-age children [9]. The association between nutritional status and educational achievement among school-age children in developing countries have not been recognized well $[9,11]$. Stunting is referred as the best indicator for a chronic type of under nutrition [9]. Children who are stunted have low ability to learn at school and poor scholastic achievement [12]. Furthermore, poor feeding practices are associated with stunted and impaired brain development $[6,13]$.

On this background, there is a necessity to overlook the relationship between nutritional status and educational performance among school-age children in the Debre 
Markos town. This study was aimed to determine nutritional status and correlation with academic performance among first cycle governmental primary school in Debre Markos Town, northwest Ethiopia.

\section{Main text \\ Methods \\ Study area, setting and period}

The study was conducted at Debre Markos town primary school. In the town, there were a total of 7473 population. Of them, 3831 were females studying in the school. Debre Markos is a city of East Gojjam Zone which is located $299 \mathrm{~km}$ away from Addis Ababa in the North. It had 15 governmental and 8 private primary schools. The study was conducted between January15 to March 17/2018.

Study design and population: An institutional-based, cross-sectional study was employed at primary school in Debre Markos town.

Sample size and sampling techniques: The sample size was determined using double population proportion by considering the following statistical assumptions: prevalence of stunting among school children $\left(\mathrm{p}_{1}\right)$ is $48 \%$ and $\mathrm{p}_{2}$ is $29 \%$ and level of significance $(\alpha)=5 \%$, at $95 \%$ level of confidence, power of the study $90 \%$ and design effect 1.5 . Finally, the overall sample size was found 442 .

Sampling procedure: Participants were carefully chosen using a multi- stage sampling technique. Out of 15 primary schools, 4 schools were selected randomly by lottery method at stage one. Students were allocated proportionally at stage two. Then participants from selected schools were selected by systematic random sampling method using students' name list by calculating ' $k$ ' value for each class.

Data collection methods: Data were collected using a pre-tested structured questionnaire and translated into the local language (Amharic version) by trained and experienced data collectors. Respondents were parents/ caregivers of the children identified in the study schools. After students were systematically selected from the schools, their household address was traced in the students' parent database. Then data collectors went to the children's house to interview parents/caretakers. Training on the standard procedures and technique how to collect data were given for the data collectors and supervisors for 2 consecutive days. The contents on questionnaires were briefly described to reduce interviewer bias.

Data processing and analysis: Data were entered into Epi-Data version 3.1 and then exported to SPSS version 20 for further analysis. Emergency Nutrition Assessment (ENA) for SMART software was used to calculate the Z-score of weight-for-age, height-for-age and weight -forheight of the children. Variables which were significant at p-value $<0.2$ in the bivariable analyses were candidate for entering into the multivariable logistic regression model to identify the independent predictors for academic performance. Before inclusion of factors, we checked multicollinearity using variance inflation factor $(\mathrm{VIF})<10$.

\section{Definition of academic performance}

The overall subjects the students were given in the academic year 2017/18 were considered to examine the academic achievements of the students. The annual average score was computed by taking the result of two consecutive semesters of the year. To verify the relationship between nutritional status and academic performance, average marks of the overall subjects the students received were either poor academic achievement or good academic achievement, in accordance with an average mark of $50 \%$. This cut off average point was decided by considering the pass mark set by Ethiopian ministry of education.

\section{Results}

\section{Socio-demographic characteristics}

A total of 436 children were included in the study with a response rate of $98.6 \%$. Of them, 245 (56.2\%) were males. The mean age of the study participants was $8.57( \pm 1.12)$ ranging from 7 to 10 years. Majority of the study participants 398 (90.8\%) were located in urban, 389 (89.2\%) orthodox and 153 (35.1\%) from grade one. Educational status of parents of the study participants showed that 81 (19.5\%) mothers and 67 (17.7\%) fathers had no formal education (Table 1).

Out of the 436 children, 37 (8.5\%) were being sick in the last semester and only 140 (32.1\%) of school-age children were attending preschool. Majority of study participants 403 (92.44) were traveled to school with in $2.18 \mathrm{~km}$ (Additional file 1: Table S1).

Level of nutritional status in study participants: The overall prevalence of stunting, underweight and wasting were $27.5 \%$ (95\% CI $23.2-31.9 \%$ ), $20.4 \%$ (95\% CI $16.5-$ $24.3 \%$ ) and $8.7 \%$ (95\% CI $6.2-11.5 \%)$ respectively. The percentage of children having any kind of under nutrition (stunting, wasting and underweight) was $56.2 \%$. The prevalence of stunting was significantly higher in males than females (Fig. 1).

Nutritional status and academic performance: In comparison of median $\mathrm{t}$-test analysis revealed that there was significant mean difference in all subject average score between children who were having any kind of undernutrition (Additional file 2: Table S2).

After adjusting factors, age, family income, nutritional indicators (WAZ and HAZ) had significant positive associations with academic achievement of students $(p<0.05)$. Age of the child (AOR $=0.177,95 \%$ CI 0.07, 0.4 ), Monthly income less $<1000.00$ birr $(\mathrm{AOR}=0.05$, 
Table 1 Socio-demographic characteristics of study participants in Debre Markos town, Northwest, Ethiopia, 2017 $(n=436)$

\begin{tabular}{|c|c|c|c|}
\hline Variable & Category & Frequency (N: 436) & Percent (\%) \\
\hline \multirow[t]{2}{*}{ Residence } & Urban & 396 & 90.8 \\
\hline & Rural & 40 & 9.2 \\
\hline \multirow[t]{4}{*}{ Age of a child (years) } & 7 & 87 & 19.9 \\
\hline & 8 & 122 & 28 \\
\hline & 9 & 109 & 25 \\
\hline & 10 & 118 & 27.1 \\
\hline \multirow[t]{2}{*}{ Sex } & Male & 245 & 56.2 \\
\hline & Female & 191 & 43.8 \\
\hline \multirow[t]{4}{*}{ Religion } & Orthodox & 389 & 89.2 \\
\hline & Muslim & 19 & 4.4 \\
\hline & Protestant & 25 & 5.8 \\
\hline & Others & 3 & 0.6 \\
\hline \multirow[t]{5}{*}{ With whom a child lives } & Mother & 37 & 8.5 \\
\hline & Father & 14 & 3.2 \\
\hline & Mother and father & 377 & 86.5 \\
\hline & Grand families & 5 & 1.14 \\
\hline & Others & 3 & 0.66 \\
\hline \multirow[t]{5}{*}{ Marital status of Parents/caregivers } & Single & 17 & 3.9 \\
\hline & Married & 367 & 84.2 \\
\hline & Divorced & 37 & 8.5 \\
\hline & Separated & 11 & 2.5 \\
\hline & Others & 4 & 0.9 \\
\hline \multirow[t]{5}{*}{ Educational status of mothers } & No formal education & 81 & 19.5 \\
\hline & Primary & 162 & 39.2 \\
\hline & Secondary & 133 & 32.2 \\
\hline & Diploma & 27 & 6.5 \\
\hline & Degree and above & 11 & 2.6 \\
\hline \multirow[t]{5}{*}{ Fathers'Educational status } & No formal education & 67 & 17.7 \\
\hline & Primary & 94 & 24.9 \\
\hline & Secondary & 98 & 25.1 \\
\hline & Diploma & 79 & 20.95 \\
\hline & Degree and above & 43 & 11.4 \\
\hline \multirow[t]{5}{*}{ Mothers' occupational status } & Housewife & 127 & 30.6 \\
\hline & Student & 9 & 2.17 \\
\hline & Government employee & 117 & 28.3 \\
\hline & Private work & 123 & 29.7 \\
\hline & Others & 38 & 9.17 \\
\hline \multirow[t]{4}{*}{ Fathers' occupational status } & Farmer & 86 & 22 \\
\hline & Merchant & 76 & 19.5 \\
\hline & Government employee & 132 & 33.7 \\
\hline & Private work & 97 & 24.8 \\
\hline \multirow[t]{3}{*}{ Family size } & $\leq 3$ & 34 & 7.8 \\
\hline & $4-5$ & 285 & 65.4 \\
\hline & $\geq 6$ & 117 & 26.8 \\
\hline \multirow[t]{3}{*}{ Monthly income } & $<1000$ & 52 & 11.9 \\
\hline & $1000-2000$ & 292 & 67 \\
\hline & $>2000$ & 92 & 20.1 \\
\hline
\end{tabular}




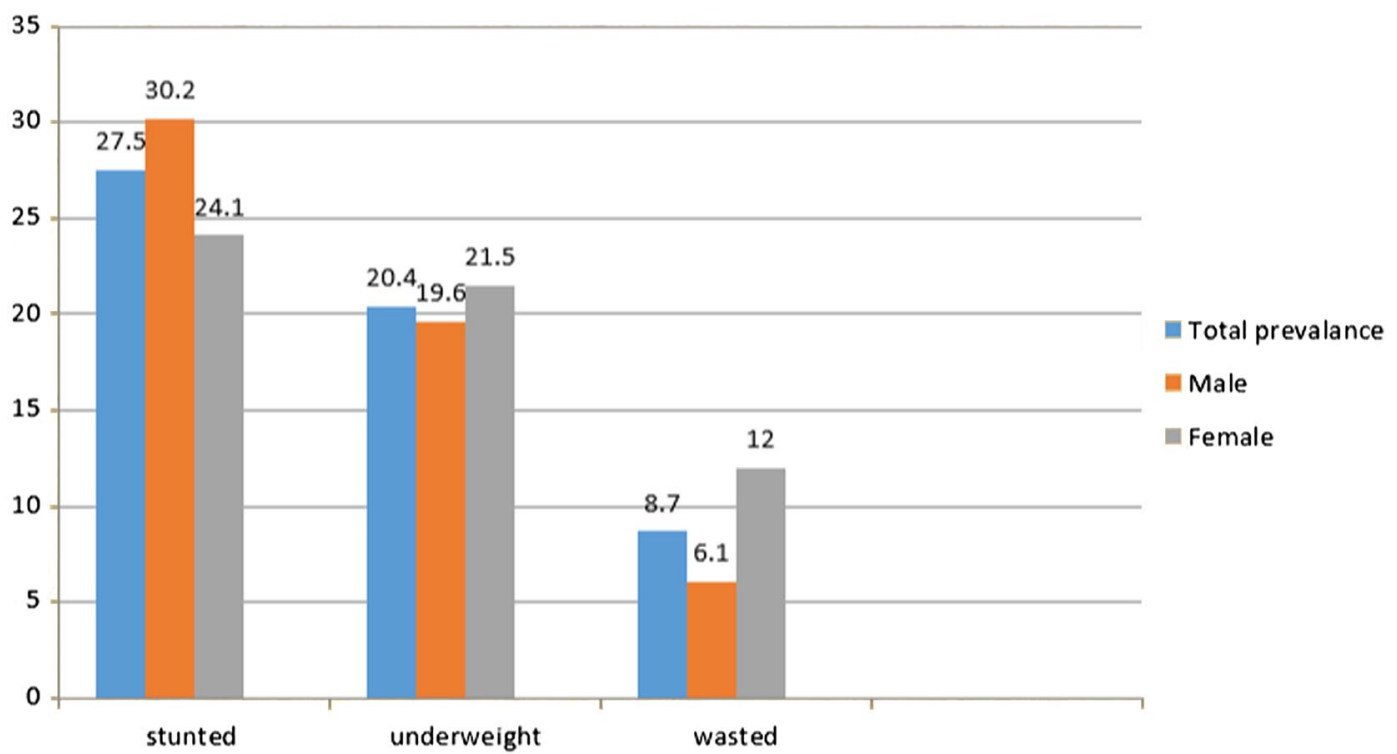

Fig. 1 Prevalence of under nutrition by gender among children in Debre Markos town, Northwest, Ethiopia, 2017 ( $n=436)$

95\% CI 0.02, 0.15), stunted children ( $\mathrm{AOR}=0.21,95 \% \mathrm{CI}$ $0.10,0.43$ ) and under-weight $(\mathrm{AOR}=0.63,95 \% \mathrm{CI} 0.26$, 0.84 ) were significantly associated with academic performance. Students those nutritional status had stunted were $79 \%$ less likely to score high academic performance as compared with normal. Students whose nutritional status had under-weight were $37 \%$ less likely to score high academic performance compared with their counterparts (Table 2).

\section{Discussions}

The aim of this study was to determine the relationship between nutritional status and academic performance among governmental primary school children. In this study, the prevalence of stunting, underweight and wasting were $27.5 \%, 20.4 \%$, and $8.7 \%$ respectively. This finding was comparable with a study done in Zambia reported that $28.9 \%$ of stunted, $14.5 \%$ of underweight and $3.9 \%$ of wasted [14]. In addition, the prevalence of stunting and wasting in this study was also in line with the findings of Sri Lanka among school-age children which indicated that the prevalence of under-nutrition in the central province was $26.6 \%$ stunted and $8.5 \%$ wasted [15], and in northwest Ethiopia, 27.1\% stunted [16]. In contrast, this finding was higher as compared to other previous studies conducted in Brazil was found (14.9\% stunted and 9.7\% wasted) [9], in Kenya (24\% stunted, $14.9 \%$ underweight, 9.7\% wasted) [17], in Nicaragua (5\% wasted) [18], in eastern Ethiopia (8.9\% stunted) [19]. The reason for this observed discrepancy might be due to sociodemographic characteristics, area of sampling and study period.
Regarding factors, the present study revealed that age and monthly income were significant factors for academic performance among primary school children. This finding was consistent with a systematic review and meta-analysis showed that there is a strong association between academic performance and socio-economic status including age [20]. Compromised socio-economic status of a family was statistically associated with poor academic performance in children [21]. Similarly, other studies done in Southeast Ethiopia [22] and in Malaysia [23] reported that minimum wealth indexed score of the family were a positive association with poor academic performance. This might be due to balanced nutritional intake is required for adequate biological functioning affect such complex brain functions as the cognitive processes related academic performance [24].

Moreover, in developing countries macronutrient and micronutrient deficiencies are a devastating problem. Consequently, this obstacle has been either direct or indirect influence on children future of life [25]. Improved nutritional status has been exposed to have a positive and direct impact on academic performance of children [4]. In the current study, under-weight and stunting were associated factors for good academic performance among school-age children. This finding is in line with a study done in Sri Lanka [26] and in Uganda [27] which revealed that child with a high score of WHZ and HAZ had good academic performance as compared to their counterparts. Also, marasmic-kwashiorkor children may acquire delay brain development. Chronic types of malnutrition (stunting) had a negative impact on 
Table 2 Bi-variable and multivariable logistic regression of variables and academic performance of study participants in Debre Markos town, Northwest, Ethiopia, March, $2017(n=436)$

\begin{tabular}{|c|c|c|c|c|c|c|}
\hline Variables & Categories & High ( $\geq 50 \%)$ & Low $(<50 \%)$ & COR & AOR & p-value \\
\hline \multirow[t]{4}{*}{ Age of child (year) } & 7 & 20.8 & 18.8 & $0.69(0.39-1.24)$ & $0.437(0.13-1.47)$ & 0.183 \\
\hline & 8 & 29.4 & 26.2 & $0.71(0.42-1.204)$ & $0.37(0.14-0.98)$ & 0.047 \\
\hline & 9 & 17.6 & 34.6 & $0.32(0.18-0.55)$ & $0.17(0.07-0.43)$ & $0.002^{*}$ \\
\hline & 10 & 32.2 & 20.4 & 1 & 1 & \\
\hline \multirow[t]{4}{*}{ Grade level } & Grade one & 33.1 & 37.7 & $0.43(0.21-0.87)$ & $0.66(0.17-2.48)$ & 0.545 \\
\hline & Grade two & 34.3 & 33 & $0.51(0.25-1.1)$ & $0.88(0.27-2.78)$ & 0.828 \\
\hline & Grade three & 18 & 22 & $0.41(0.19-1.86)$ & $0.75(0.25-2.22)$ & 0.606 \\
\hline & Grade four & 14.7 & 7.3 & 1 & 1 & \\
\hline \multirow[t]{5}{*}{ Educational status of mothers } & No formal education & 18.8 & 21.5 & $2.99(0.74-12.03)$ & $1.26(0.26-5.9)$ & 0.76 \\
\hline & Primary & 40 & 35.6 & $3.84(0.98-5.01)$ & $2.12(0.46-9.59)$ & 0.32 \\
\hline & Secondary & 34.7 & 28.3 & $4.19(1.06-16.6)$ & $2.07(0.44-9.79)$ & 0.35 \\
\hline & Diploma & 5.3 & 10.5 & $1.38(1.38-7.7)$ & $1.45(0.24-8.64)$ & 0.68 \\
\hline & Degree and above & 1.2 & 4.2 & 1 & 1 & \\
\hline \multirow[t]{3}{*}{ Family size } & $\leq 3$ & 11.8 & 2.6 & 1 & 1 & \\
\hline & $4-5$ & 61.6 & 70.2 & $0.19(0.07-0.51)$ & $0.54(0.08-1.78)$ & 0.17 \\
\hline & $\geq 6$ & 26.5 & 27.2 & $0.21(0.07-0.59)$ & $0.21(0.06-1.6)$ & 0.13 \\
\hline \multirow[t]{3}{*}{ Monthly income } & $<1000$ & 4.9 & 20.9 & $0.04(0.02-11)$ & $0.05(0.02-0.15)$ & $0.001^{*}$ \\
\hline & $1000-2000$ & 62.9 & 72.3 & $0.18(0.09-0.34)$ & $0.18(0.08-0.37)$ & $0.001 *$ \\
\hline & $>2000$ & 32.2 & 6.8 & 1 & 1 & \\
\hline \multirow[t]{2}{*}{ Sickness in last semester } & Yes & 79.6 & 64.9 & $2.107(1.37-3.23)$ & $0.383(0.153-1.95)$ & 0.43 \\
\hline & No & 20.4 & 35.1 & 1 & 1 & \\
\hline \multirow[t]{2}{*}{ Absenteeism } & Non absent & 24.9 & 7.9 & $3.89(2.13-7.08)$ & $2.14(0.96-11.54)$ & 0.08 \\
\hline & Absent & 75.1 & 92.1 & 1 & 1 & \\
\hline \multirow[t]{2}{*}{ Study time in home } & No & 4.5 & 13.6 & $0.29(0.14-0.62)$ & $0.82(0.45-1.48)$ & 0.51 \\
\hline & Yes & 95.5 & 86.4 & 1 & 1 & \\
\hline \multirow[t]{2}{*}{ WAZ } & Under weight & 10.2 & 33.5 & $0.22(0.13-0.37)$ & $0.63(0.26-0.84)$ & $0.003^{*}$ \\
\hline & Normal & 89.8 & 66.5 & 1 & 1 & \\
\hline \multirow[t]{2}{*}{$\mathrm{HAZ}$} & Stunted & 16.3 & 41.9 & $0.27(0.17-1.22)$ & $0.21(0.10-0.43)$ & $0.001^{*}$ \\
\hline & Normal & 83.7 & 58.1 & 1 & 1 & \\
\hline \multirow[t]{2}{*}{ WHZ } & Wasted & 4.5 & 14.1 & $0.28(0.13-0.59)$ & $0.80(0.54-1.2)$ & 0.06 \\
\hline & Normal & 95.5 & 85.9 & 1 & 1 & \\
\hline
\end{tabular}

* Significant factors in the multivariable analysis

child cognitive development [20]. Similarly, a study done in Southeast Ethiopia revealed that higher score of HAZ was significantly associated with a higher academic score [20]. In this study, wasting (WHZ) was not statistical association with child academic performance. This nonsignificance effect might be due to the fact that wasting is acute malnutrition which implies a temporary nutritional disorder that may not negative substantial impact on academic performance $[28,29]$.

\section{Conclusion}

The study revealed that indicators of undernutrition were prevalent among Debre Markos town primary school children. Age, income, HAZ and WAZ scores showed significant association with academic performance. Therefore, the government should paid attention to implement nutrition screening program and intervention strategy to improve academic performance at primary school children.

\section{Limitation of the study}

Finally, some important limitations of this study was cross-sectional nature of the study could not establish a cause and effect relationship between the dependent and independent variables. The other limitation of the study is that it was done in an urban areas which may inadequate representative for rural area. 


\section{Additional files}

Additional file 1: Table S1. General characteristics of study participants in Debre Markos town, March, 2017 ( $n=436)$

Additional file 2: Table S2. Prevalence of low educational performance (marks $<$ median of student result of nutritional status of children, Debre Markos, $2017(n=436)$

\section{Authors' contributions}

BA, MT, SB and FW were participated in proposal writing, analyzing the data, and drafting the paper. MT and FW prepared the manuscript for publication. All authors read and approved the final manuscript.

\section{Acknowledgements}

The author's deep gratitude goes to Debre Markos University, college of medicine and health sciences for proper review and approval of this paper. The authors would also like to extend their gratitude to Debre Markos town educational office and primary schools in the town, data collectors, and supervisors for valuable contribution for the success of this study.

\section{Competing interests}

The authors declare that they have no competing interests.

\section{Availability of data and materials}

Additional file: data collection tool.

Data set: The datasets used and/or analyzed during the current study are available from the corresponding author on reasonable request.

\section{Consent to publication}

Not applicable.

\section{Ethics approval and consent to participate}

The study was carried out after getting approval from Debre Markos University institutional review board (IRB). Written permission was obtained from educational office and administrative leaders of respective schools. The verbal (nonwritten) consent was obtained because written consent needed a certain level of education to read and sign the consent. Participants had the right to refrain from answering some questions or withdraw from the study process at any time. To maintain confidentiality, each and every one collected data were coded and locked in a separate room prior to enter into the computer. Following entered into the computer all data were protected by password.

\section{Funding}

Not applicable.

\section{Publisher's Note}

Springer Nature remains neutral with regard to jurisdictional claims in published maps and institutional affiliations.

\section{Received: 24 July 2018 Accepted: 1 November 2018}

Published online: 09 November 2018

\section{References}

1. Aregaw E. Multilevel analysis of factors affecting academic achievement of primary school students, Ethiopia, Gondar. Imperial J Interdiscip Res. 2016;2(2):1362-2454.

2. Rastogi P, Nagesh K, Yoganarasimha K. Estimation of stature from hand dimensions of north and south Indians. Leg Med. 2008;10(4):185-9.

3. Chambers R. Back matter-challenging the professions. Challenging the professions: frontiers for rural development. Rugby: Practical Action Publishing; 1993. p. 122-43.
4. Opoola F, Adebisi SS, Ibegbu AO. The Study of nutritional status and academic performance of primary school children in zaria, Kaduna state, Nigeria. Annal Bioanthropol. 2016:4(2):96.

5. Endalew B, Muche M, Tadesse S. Assessment of food security situation in Ethiopia: a review. Asian J Agric Res. 2015;9(2):55-68.

6. Grantham-McGregor SM, Fernald LC, Sethuraman K. Effects of health and nutrition on cognitive and behavioural development in children in the first three years of life Part 2: infections and micronutrient deficiencies: iodine, iron, and zinc. Food Nutr Bull. 1999;20(1):76-99.

7. Senbanjo IO, Oshikoya KA, Odusanya OO, Njokanma OF. Prevalence of and risk factors for stunting among school children and adolescents in Abeokuta, Southwest Nigeria. J Health Popul Nutr. 2011;29(4):364.

8. Duyar I, Pelin C. Estimating body height from ulna length: need of a population-specific formula. Eur J Anthropol. 2010;1(1):11-7.

9. Sarma MSWD, Sivananthawerl T. The effects of nutritional status on educational performance of primary school children in the plantation sector in Nuwara Eliya Educational Zone. Trop Agric Res. 2013;24(3):14-203.

10. Anuar MLC, Low W, Harun F. Effects of nutritional status on academic performance of Malaysian primary school children. Asia Pac J Public Health. 2005;17:7-81.

11. Galal $\mathrm{OHJ}$. The relationship between nutrition and children's educational performance. Br J Nutr. 2003;25:11-20.

12. Shariff ZMBJ, Johnson NE. Nutrition and educational achievement of urban primary school children in Malaysia. Asia Pac J Clin Nutr. 2000:9(4):73-264.

13. Mendez MA, Adair LS. Severity and timing of stunting in the first two years of life affect performance on cognitive tests in late childhood. J Nutr. 1999;129(8):1555-62.

14. al GMe: lodine deficiency, anthropometric status cognitive function of school age children in Hawassa town, Southern Ethiopia. Awassa: Hawassa University; 2009.

15. Herrador Z. Cross-sectional study of malnutrition and associated factors among school aged children in rural and urban settings of Fogera and LiboKemkem Districts. Ethiopia. PLoS ONE. 2014;9:9.

16. McClung IP. Growth deficits in school age children in Brazil. Am J Clin Nutr. 2008:50:687-96.

17. Degarege D, Degarege A, Animut A. Undernutrition and associated risk factors among school age children in Addis Ababa, Ethiopia. BMC Public Health. 2015;15(1):375.

18. Mesfin FBY, Worku A. Prevalence and associated factors of stunting among primary school children in Eastern Ethiopia. Nutr Diet Suppl. 2015;7:7-61.

19. Kar BRS, Chandramouli BA. Cognitive development in children with chronic protein energy malnutrition. Behav Brain Funct Nicaregu. 2008;4:31.

20. Jhanji S, Thomas B, Ely A, Watson D, Hinds C, Pearse R. Mortality and utilisation of critical care resources amongst high-risk surgical patients in a large NHS trust. Anaesthesia. 2008;63(7):695-700.

21. Jamison DT. Child malnutrition and school performance in China. J Dev Econ. 1986;20(2):299-309

22. MoH. United Nations International Children's Education Fund (UNICEF), author Inc The 1999 National micronutrient survey report. UNICEF. 2001;2001:93.

23. Hodgkin E. Nutrition and academic achievement: Are they related?. An international journal of faith, thought and action 2007.

24. Aturupane HGP, Wisniewski S. The impact of School Quality, SocioEconomic Factors and Child Health on Students' Academic Performance. Evidence from Sri Lankan Primary Schools. 2002

25. Mian RM. The nutritional status of school-aged children in an urban squatter settlement in Pakistan. Pak J Nutr. 2011:1(3):121-3.

26. McKnelly: nutrition and school performance. livestrongcom 2015.

27. Katona P. The interaction between nutrition and infection. Clin Infect Dis. 2008;46:8-1582.

28. Kleinman RE. Diet, breakfast, and academic performance in children. Ann NutrMetab. 2002;46(1):24-30.

29. Frongillo EA. Food stamp program participation is associated with better academic learning among school children. J Nutr. 2006;136:80-1077. 